\title{
Multiple Variations in Carotid Arteries: Lower Common Carotid Bifurcation, Hypoplastic and Tortuous Internal Carotid Artery
}

\author{
Oguz Kadir Egilmez ${ }^{1^{*}}$, Lokman Uzun ${ }^{2}$, M. Tayyar Kalcioglu ${ }^{2}$ \\ and Muhammet Tekin ${ }^{2}$ \\ ${ }^{1}$ ENT Clinic, Malkara State Hospital, Tekirdag, Turkey. \\ ${ }^{2}$ Department of Otorhinolaryngology, Faculty of Medicine, Istanbul Medeniyet University, \\ Istanbul, Turkey.
}

Authors' contributions

This work was carried out in collaboration between all authors. Author OKE wrote the first draft of the manuscript and managed the literature searches. Author $L U$ designed the report and made the final control. Author MTK made the final control. Author MT wrote the manuscript. All authors read and approved the final manuscript.

Article Information

DOI: 10.9734/BJMMR/2017/33449

Editor(s):

(1) Amit Goyal, Department of Otorhinolaryngology, All India Institute of Medical Sciences (AIIMS), India. (2) Sarah Ralte, Department of Anatomy, North Eastern Indira Gandhi Regional Institute of Health and Medical Sciences (NEIGRIHMS), Shillong, India.

(3) Patorn Piromchai, Department of Otorhinolaryngology, KhonKaen University, Thailand. Reviewers:

(1) Sergey Kozlov, Russian Cardiology Research and Production Complex, Moscow, Russia.

(2) Myoung Soo Kim, Pohang SM Christianity Hospital, Gyeongbuk, Republic of Korea. Complete Peer review History: http://www.sciencedomain.org/review-history/19308

Case Study

Received $16^{\text {th }}$ April 2017

Accepted $30^{\text {th }}$ May 2017

Published $2^{\text {nd }}$ June 2017

\section{ABSTRACT}

Aim: During the neck surgery, vascular complications could be encountered in the cases with vascular anomalies. To reduce the complication rates and minimize operative morbidity and mortality, it is important to know the normal vascular anatomy of the neck and its related anomalies.

Presentation of Case: In this report, a 60-year-old male patient diagnosed with laryngeal carcinoma was presented. Total laryngectomy and bilateral functional neck dissection was performed to the patient with the diagnosis of squamous cell carcinoma of the larynx. During the 
neck dissection, bifurcation of right common carotid artery was detected lower than the usual localization, hypoplastic as well as tortuous internal carotid artery was seen on the same side. Multiple fusiform dilatation with narrowing of the right internal jugular vein (IJV) was also detected.

Discussion: Previously, there are several reported anomalies in the literature. The bifurcation of the common carotid arteries may be lower or higher than the normal levels. Also tortuous arteries can be seen during surgery and it may be asymptomatic if it is mild otherwise may lead to ischaemia of the organs if it is severe. The cause could be genetic, or may be thickening of the arteries.

Conclusion: We wanted to emphasize the importance of the knowledge of normal anatomy and also anomalies of vessels of the head and neck region and implications of these anomalies were discussed under the light of literature.

Keywords: Carotid; bifurcation; variation; tortuous; hypoplastic.

\section{INTRODUCTION}

Several important anatomical structures like carotid arteries, jugular veins, vagus nerve and its branches, esophagus and trachea are harbored in the neck [1]. Accidental injuries to these vital structures may cause life-threatening and serious complications during the neck surgery. Surgeons must be well-versed in anatomy of the great vessels of the neck and its anomalies before undertaking such an operation. Previously, in the literature, several carotid artery anomalies and anatomic variations which are agenesis, aplasia, hypoplasia, trifurcation, curved, kinked, anomalous origin, non-bifurcated cervical carotid artery, independent origins, aberrant artery, lower carotid bifurcation, and tortuosity were reported [1-7]. In some cases, bifurcation of common carotid artery (CCA) is seen lower than the usual localization, like lower cervical or thoracic bifurcation and tortuosity of carotid artery may be seen but in our knowledge, there has been no report in which tortuous internal carotid artery and lower cervical CCA bifurcation are co-existent. In this article, we report a 60-year-old male patient with lower cervical bifurcation of CCA and associated hypoplastic and tortuos internal carotid artery, and underline the importance of variations of carotid arteries during the neck dissection.

\section{PRESENTATION OF CASE}

A 60-year-old male patient was admitted to our clinic with dyspnea and dysphonia for one year. On laryngeal endoscopy, tumoral mass was seen on upper surfaces of bilateral vocal folds. MRI showed a heterogeneous hypervascular mass on the level of vocal folds. Microsurgical laryngeal biopsy was performed and the result was consistent with squamous cell carcinoma. Total laryngectomy and bilateral functional neck dissection was planned to the patient. During the neck dissection on the right side, carotid bifurcation was detected lower than the usual anatomical position, and the internal carotid branch was found to be tortuous and also hypoplastic. Multiple fusiform dilatation with narrowing of the right internal jugular vein (IJV) was also detected (Fig. 1). Keeping in mind these anatomical variations, much care was taken during the surgery and neck dissection was performed meticulously to avoid any damage to the carotid arteries. Operation and postoperative period were uneventful.

\section{DISCUSSION}

The bifurcation of CCA is usually located at approximately $\mathrm{C} 4$ vertebra level which corresponds with the upper border of lamina of thyroid cartilage. In a report by lto et al. the height of bifurcation of CCA was researched on cadaver dissection and rates of high, standard, and low bifurcation was found to be $31.2 \%$, $57.5 \%$, and $11.3 \%$, respectively [8]. Lo et al. [1] made an experiment on 67 cadavers and reported that CCA bifurcation was detected at the level of the body of hyoid bone in $40 \%$, at the level of superior border of thyroid cartilage in $39 \%$, at the level of tip of greater horn of hyoid bone in $15 \%$, and at the level of body of thyroid cartilage in $6 \%$. They also reported that origin of the superior thyroid artery was related to the level of the CCA bifurcation. Presence of high CCA bifurcation should alert surgeons that the superior thyroid artery may arise from the CCA and then the hypoglossal nerve is more vulnerable [1].

In 1906, Orr first reported the lower cervical bifurcation of CCA [9]. Gulsen et al. [10] reported bilateral low-lying bifurcation of the common carotid artery. In that case, CCA bifurcation was 
located between the body of $\mathrm{C} 5$ and $\mathrm{C} 6$ vertebra on the left side and between the body of $\mathrm{C} 6$ and $\mathrm{C} 7$ on right side. They also reported that they had some difficulties (i.e. during traction of the tissues to expose the disc spaces and insertion of the cages into the cervical interspaces) in a cervical dissection in a patient with low-lying CCA bifurcation. Uzun et al. [7] reported a 62year-old male patient with bilateral lower cervical bifurcation of CCA.

There is clinical significance in many respects of the tortuous and lower bifurcation of the carotid artery and fusiform dilatations of the internal jugular vein. First, these cases with vascular anomalies tend to result in vascular complications. Any serious damage to the major vascular structures may lead to life-threatening consequences. Second, especially in neck dissection of the cancer patients; The surgical dissection is more difficult than the normal patients. We experienced this kind of difficulty in our present case with vascular anomaly. Third, the opration time is expected to be longer than the normal cases. Fourth, in some certain surgeries, to reach the operation site through the neck may present some difficulties. Gulsen et al. had encountered difficulties in a cervical discectomy operation in patient with lower bifurcation of the carotid artery [10]. Fifth, during the surgery, changed relationship among the anatomical structures because of vascular anomaly may cause inadvertent damage to neighboring tissue. Sixth, these challenges and obstacles, may reduce the success of the operation.

Level III are located between a horizontal plane defined by the inferior border of the cricoid cartilage and the hyoid superiorly. The sternohyoid muscle marks the anterior limit of level III, and the posterior border is the posterior border of the sternocleidomastoid (SCM) muscle. Level IV are located between the inferior border of the cricoid cartilage and the clavicle, and, the posterior border is the posterior border of the SCM muscle and the anterior boundary is the sternohyoid muscle. In our case, during the neck dissection, carotid bifurcation was detected almost $2 \mathrm{~cm}$ below its usual location (the junction of the level III and IV) and the internal carotid artery was hypoplastic and tortuous. Multiple fusiform dilatations and narrowings of IJV was also detected at the same side of the neck (Fig. 1). Because of variations of carotid arteries and jugular vein, surgery was performed meticulously to avoid any damage to vascular structures. Operative and postoperative periods were uneventful, but only dissection of the carotid fascia took more time than usual during the neck dissection.

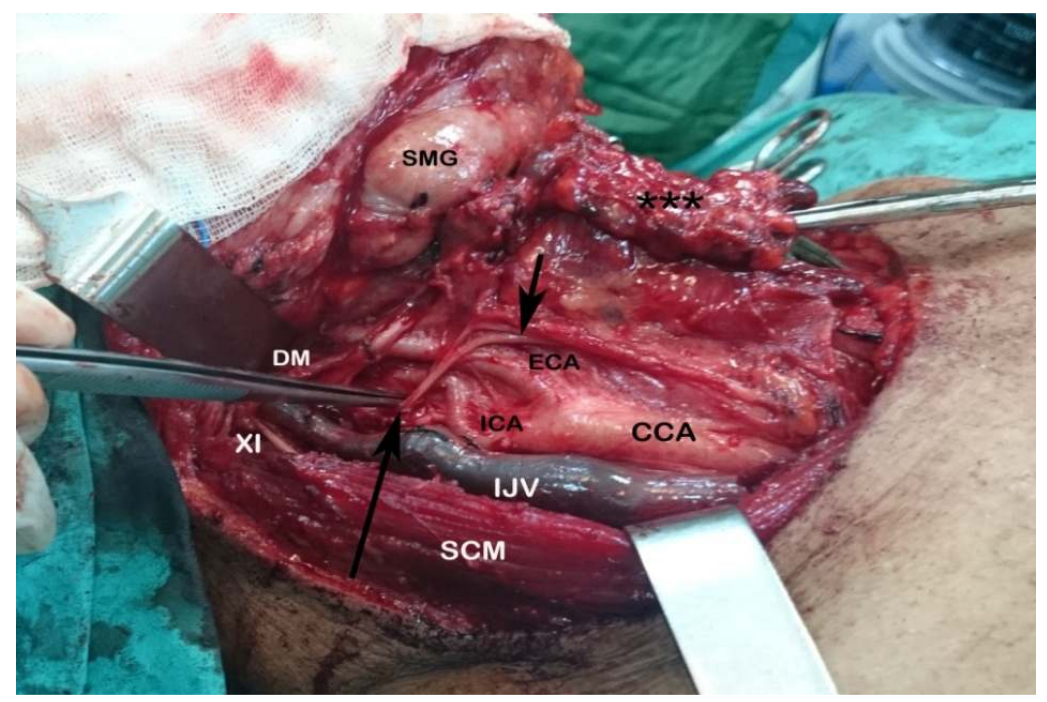

Fig. 1. Lower bifurcation of common carotid and tortuosity and hypoplasia of internal carotid artery were detected during the neck dissection. Multiple fusiform dilatation with narrowing of the right IJV was also detected

(CCA: Common carotid artery, ICA: Internal Carotid artery, ECA: External carotid artery, SCM: Sternocleidomastoid muscle, SMG: Submandibular gland, XI: CN XI, DM: Posterior belly of digastric muscle, short arrow: Ansa cervicalis, long arrow: Hypoglossal nerve,

***: Dissection material) 


\section{CONCLUSION}

During the neck surgery, the cases with vascular anomalies and variations may lead to vascular complications. To reduce the complication rates and to help minimize operative morbidity and mortality, a clear understanding of normal anatomy as well as knowledge of anatomical variations of the vasculature of head and neck region is necessary.

\section{CONSENT}

All authors declare that written informed consent was obtained from the patient for publication of this case report and accompanying images.

\section{ETHICAL APPROVAL}

It is not applicable.

\section{COMPETING INTERESTS}

Authors have declared that no competing interests exist.

\section{REFERENCES}

1. Lo A, Oehley M, Bartlett A, Adams D, Blyth P, Al-Ali S. Anatomical variations of the common carotid artery bifurcation. ANZ J Surg. 2006;76:970-2.

2. Lee JH, Oh CW, Lee SH, Han DH. Aplasia of the internal carotid artery. Acta Neurochir. 2003;145:117-25.
3. Mumoli N, Cei M. Asymptomatic carotid kinking. Circulation. 2008;72:682-3.

4. Cakirer S, Karaarslan E, Kayabali M, Rozanes I. Separate origins of the left internal and external carotid arteries from the aortic arch: MR angiographic findings. Am J Neuroradiol. 2002;23: 1600-2.

5. Hosokawa S, Mineta H. Tortuous internal carotid artery presenting as a pharyngeal mass. J Laryngol Otol. 2010;124:1033-6.

6. Kaliaperumal C, Jain N, McKinstry CS, Choudhari KA. Carotid "Trifurcation" aneurysm: Surgical anatomy and management. Clin Neurol Neurosurg. 2007;109:538-40.

7. Uzun L, Kokten N, Kilicaslan A, Tasel B, Kalcioglu MT, Tekin M. Bilateral Lower Cervical Bifurcation of the Common Carotid Artery. Case Rep Otolaryngol. 2013;2013:894-804.

8. Ito H, Mataga I, Kageyama I, Kobayashi K. Clinical anatomy in the neck region-the position of external and internal carotid arteries may be reversed. Okajimas Folia Anat Jpn. 2006;82:157-67.

9. Orr AE. A rare anomaly of the carotid arteries (Internal and External). J Anat Physiol. 1906;41:51.

10. Gulsen S, Caner H, Altinors N. An anatomical variant: Low-lying bifurcation of the common carotid artery and its surgical implications in anterior cervical discectomy. J Korean Neurosurg Soc. 2009;45:32-4.

(C) 2017 Egilmez et al.; This is an Open Access article distributed under the terms of the Creative Commons Attribution License (http://creativecommons.org/licenses/by/4.0), which permits unrestricted use, distribution, and reproduction in any medium, provided the original work is properly cited.

Peer-review history:

The peer review history for this paper can be accessed here: http://sciencedomain.org/review-history/19308 